\title{
Evolution of marriage systems
}

\author{
Laura Fortunato \\ Institute of Cognitive and Evolutionary Anthropology \\ University of Oxford \\ 64 Banbury Road, Oxford OX2 6PN, UK \\ laura.fortunato@anthro.ox.ac.uk \\ $+44(0) 1865284971$ \\ Santa Fe Institute \\ 1399 Hyde Park Road \\ Santa Fe, NM 87501, USA
}

Published as: Fortunato, L. (2015) Evolution of marriage systems. In Wright, J. D. (Ed.), International Encyclopedia of the Social \& Behavioral Sciences, 2nd ed., vol. 14, pp. 611-619. Oxford: Elsevier. https://doi .org/10.1016/B978-0-08-097086-8.81059-4. 


\section{Contents}

1 Definition of the subject $\quad 4$

2 Key concepts 5

2.1 What is marriage $\ldots \ldots \ldots \ldots \ldots \ldots \ldots \ldots \ldots$

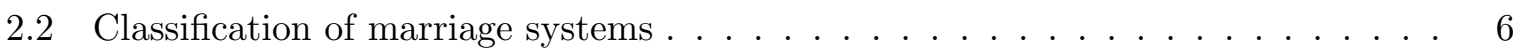

2.3 Marriage, mating, and reproduction $\ldots \ldots \ldots \ldots \ldots$

3 Evolutionary perspectives on marriage systems 10

3.1 Polygyny as the "default" mating and marriage system . . . . . . . . . . . . 11

3.2 Polygynous marriage as resource defense polygyny $\ldots \ldots \ldots \ldots$

3.3 The polygyny threshold model, female choice, and male coercion . . . . . . . . 14

3.4 Monogamous marriage as socially imposed monogamy . . . . . . . . . . . 16

3.5 Monogamous marriage as "monogamous inheritance" . . . . . . . . . . . . . 18

3.6 Polyandrous marriage as a response to ecological challenges $\ldots \ldots \ldots$

4 Concluding remarks $\quad 22$

$\begin{array}{ll}\text { References } & 23\end{array}$ 


\begin{abstract}
A marriage system is the set of rules and norms that regulate reproduction in a given human society. This article provides an overview of key concepts and general themes in the study of their evolution. The focus is on the number of spouses allowed (i.e. whether marriage is monogamous or polygamous), and the social and ecological factors associated with this aspect of the marriage system.
\end{abstract}

Keywords marriage, kinship, family, inheritance, monogamy, polyandry, polygyny, polygamy, evolution of human social behaviour, human reproduction

Cross-references Evolution of human mate choice, Evolution of kinship 


\section{Definition of the subject}

A marriage system is the set of rules and norms that regulate reproduction in a given human society. This is closely linked to the set of rules and norms that shape interactions based on relatedness, the kinship system. For example, some societies draw a distinction between crossand parallel cousins. Your cross-cousins are the offspring of your parents' opposite-sex siblings (i.e. the children of your father's sisters and of your mother's brothers), your parallel cousins are the offspring of your parents' same-sex siblings (i.e. the children of your father's brothers and of your mother's sisters). The kinship system of one of these societies may emphasize social ties among cross-cousins over those among parallel cousins. The marriage system may stipulate marriage between cross-cousins as the preferred or prescribed form.

Both relatedness and reproduction play a role in, and are shaped by, the evolutionary process. Hence, the study of kinship and marriage systems figures prominently in biological approaches to human behavior. At the same time, it is a core topic in social and cultural anthropology. This article focuses on research on marriage systems at the interface of the two fields. A complementary treatment of kinship systems can be found in Evolution of kinship.

Broadly, the rules and norms encoded in the marriage system pertain to two domains. One deals with definition of the socially acceptable marital arrangements: for example, whom one is allowed or not allowed to marry, whether particular categories of individuals are preferred or prescribed marriage partners, and whether multiple spouses are allowed. The other domain deals with the flow of resources at marriage. This includes the transfer of material property (e.g. dowry, where the bride's family transfers land and/or other resources to the newly-wed), the provision of labor (e.g. brideservice, where the groom assists the bride's family in productive activities), and the movement of individuals (e.g. virilocal residence, where the newly-wed take up residence with or near the groom's kin).

Both domains have been approached from an evolutionary perspective (see reviews and discussion in Low, 2003, 2007). Rather than attempting an exhaustive review of the literature, my aim here is to outline the general principles derived from biology that are used to frame questions about the evolution of marriage systems. To this end, I restrict the focus of the article to the rules and norms that regulate the number of spouses allowed (i.e. whether marriage is monogamous or polygamous) and their environmental correlates, both social and ecological. 


\section{Key concepts}

I begin by introducing some key concepts in the study of marriage systems, with the aim of "unpacking" the relationship between marriage, mating, and reproduction.

\subsection{What is marriage?}

The definition of marriage system given above is intentionally vague. Clearly, this is tied to the definition of marriage itself; because of the diversity of family arrangements across human societies, development of a definition that applies universally (and that is universally accepted as such!) has proved surprisingly difficult (Holy, 1996, pp. 48-50).

For the purposes of this article marriage can be defined as a socially recognized union, normatively endorsed, between two or more individuals. This may involve (i) restrictions on sexual relations, typically allowed exclusively between spouse(s), and (ii) the investment of resources in any children associated with the union. Resources may be "social" (e.g. political status) or physical (e.g. material property), and they may be invested by the spouses themselves and/or by their kin. Where the resources involved are substantial, marriage may be linked to the notion of legitimacy, which serves to channel them to "appropriate" individuals.

In these key aspects marriage is distinct from mating, irrespective of whether and to what degree pre- and/or extra-marital sexual relations are tolerated (Parkin, 1997, pp. 39-40; discussed further below). Evolutionary approaches have tended to view different marriage systems as alternative reproductive strategies; therefore, this article focuses exclusively on heterosexual marriage. The implications of homosexual marriage for anthropological theory are discussed in Levine (2008).

From a cross-specific perspective, marital unions with parental investment are analogous to non-human mating partnerships where mates cooperate in providing resources (e.g. food, protection) to the offspring. There are some peculiarities, however (Irons, 1983, p. 190). In addition to cooperating in offspring provisioning, marital partners may engage in an extended pattern of reciprocal provisioning. This usually involves a division of labor between the sexes in productive activities: thus, the marital union provides access to resources that are controlled or produced by the opposite sex. Alongside reciprocal provisioning, marital partners entertain relationships of cooperation and reciprocity with several other adult individuals, while main- 
taining a relatively stable sexually exclusive bond with each other. In non-human species mate provisioning tends to be associated with copulation (e.g. courtship feeding), and transfers of resources in this context typically flow from males to females rather than reciprocally (Stevens and Gilby, 2004).

A further peculiar aspect of marital unions, compared to non-human mating partnerships, is the potential direct involvement of third parties (Low, 2003, 2007). For example, parents may be actively involved in selecting a spouse for their offspring; together with other kin, they may exert control over the timing of the union. By contrast, non-human mating partnerships are typically the outcome of direct interactions between two or more individuals. Of course, wider networks of interactions play a role in the formation of mating partnerships in any social species: for example, coalitionary alliances between males or within-group status-ranking may affect the sequence and timing of the partnerships. This, however, is distinct from the direct involvement of third parties in the arrangement of marital unions in humans.

In the evolutionary literature these peculiarities have often been portrayed as cultural "frills" attached to the human mating system. In one view, the marriage system is simply a set of rules and norms grafted onto the mating system (e.g. Low, 2003, 2007). Another view draws on the distinction, developed for non-human species, between the social mating system and the sexual/genetic one. The former captures the pattern of social living arrangements (e.g. shared use of territory), the latter captures the network of sexual interactions and the resulting genetic relationships. In this view, the marriage system is analogous to the social mating system (e.g. Reichard, 2003, p. 4). As I discuss below, these and related approaches fail to account for several nuances in the interplay between marriage, mating, and reproduction.

\subsection{Classification of marriage systems}

In classifying marriage systems, a useful starting point is the distinction between two major exclusive types, based on the number of concurrent spouses allowed: "monogamy" (individuals may be married to only one spouse at any one time) and "polygamy" (individuals may be married to multiple spouses at any one time). Within polygamy, "polyandry" and "polygyny" refer to multiple concurrent spouses allowed for women and for men, respectively.

These labels derive from combination of the Greek words for single, sole (mónos) or many (polús) with the words for marriage (gámos), man (anér), or woman (guné). Thus, polygamy 


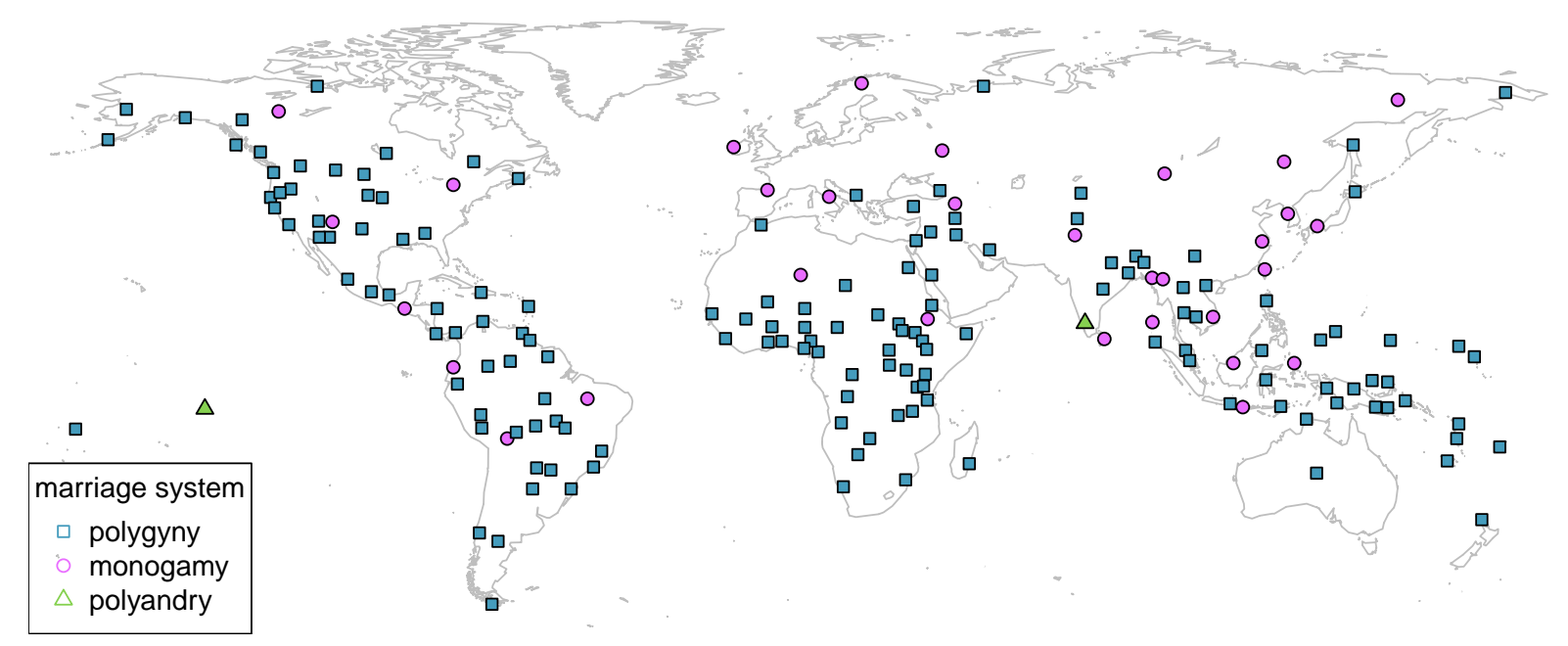

Figure 1: Distribution of marriage systems across societies in the Standard Cross-Cultural Sample (Murdock and White, 1969), based on data from variable 79 (White et al., nd). This variable captures the social composition of the prevailing form of family organization, with monogamy defined in terms of the prohibition or disapproval of polygyny (Murdock and Wilson, 1972). The two categories for polygynous marriage are collapsed (limited polygyny, i.e. less than $20 \%$ of men married to plural wives, and general polygyny, i.e. more than $20 \%$ of men married to plural wives).

is a generic term that captures any form of non-monogamous marriage, even though in the popular press it is commonly used to indicate the marriage of a man to multiple wives instead. In what follows, my use of the labels reflects the technical definitions given above, consistent with their etymology.

Classification of marriage systems as monogamous, polyandrous, or polygynous has proved particularly fruitful. This is likely because the relevant rules are readily observed, even in the absence of individual-level data on marital status; consequently, ethnographies typically include information on this aspect of the marriage system. In the Standard Cross-Cultural Sample (Murdock and White, 1969), a sample of 186 societies that is broadly representative of human cultural variation as reflected in the ethnographic record, classification of marriage systems into exclusive types yields 31 societies (17\%) coded as monogamous, $2(1 \%)$ as polyandrous, and 153 $(82 \%)$ as polygynous (see discussion below). Figure 1 shows their geographical distribution.

This classification captures variation along the synchronic dimension; additionally, there is variation along the diachronic dimension, which deals with whether individuals are allowed multiple non-concurrent spouses over the course of their lifetime (Harrell, 1997, p. 22). In 
practice, the diachronic dimension relates to whether divorced and/or widowed individuals are allowed to remarry, which is not universally the case. For example, remarriage may be allowed for only one of the sexes (typically men).

Somewhat confusingly, in the evolutionary literature a marriage system that enforces monogamy but allows multiple non-concurrent spouses is known as both "successive monogamy" and "successive polygamy"; the terms "serial" and "sequential" are also used (Mealey, 2000, p. 321). This confusion reflects the tension between the usefulness of a simple classification scheme, and its limitations in describing the relationship between the rules encoded in the marriage system, actual behavior, and the reproductive implications of each. Evolutionary approaches have been especially prone to confusion: with their focus on reproduction, they have often drawn inferences about mating behavior from information on the marriage system, which can be problematic. I return to this issue below; first, it is useful to clear up two additional potential points of confusion with the classification scheme outlined above.

One point of confusion results from the opposition of monogamy and polygamy as exclusive types. This does not imply that the two marriage systems are "symmetric" with respect to the marital arrangements allowed: while polygamous unions are forbidden in a monogamous system, the reverse is not true, i.e. monogamous unions are of course allowed in a polygamous system (discussed below).

The other point of confusion is that the terms "polygyny" and "polyandry" are not used consistently in the anthropological literature. Polygyny generally refers to systems where multiple concurrent spouses are allowed for men but not for women, whereas polyandry is often used for systems where multiple concurrent spouses are allowed for women, even when they are not forbidden for men. The rationale appears to be that in these so-called polyandrous societies multiple concurrent spouses are customary for women, but they are only occasional occurrences for men (discussed below). Terms that more accurately describe these scenarios ("polygynandry" or, better, "polyandrogyny") are used rarely and inconsistently in anthropology.

\subsection{Marriage, mating, and reproduction}

We can now return to the issue we touched on in the preceding two sections, of how to best characterize the interplay between marriage, mating, and reproduction. A general framework includes four nested levels. At one end is the marriage system, defined above as the set of 
rules and norms that regulate reproduction. This maps onto the actual pattern of marital arrangements. In turn, this maps onto the actual pattern of mating interactions, both within and outside of marriage. A final distinction is between mating behavior and the genetic level: not all sexual interactions result in the production of children, through a host of mechanisms ranging from sperm competition (see Evolution of human mate choice) to contraception.

We can illustrate this general framework with reference to two fictitious societies. In one society men are allowed multiple concurrent spouses, but remarriage is forbidden (the marriage system); in any case, only a small fraction of men typically engages in plural concurrent unions (the pattern of marital arrangements). In the other society monogamous marriage is enforced, but remarriage is allowed for both men and women (the marriage system); as a result, a large fraction of the population engages in plural non-concurrent unions (the pattern of marital arrangements). In both societies mating is effectively polygamous, because pre- and extra-marital sexual relationships are common (the pattern of mating interactions). Finally, reproduction tends to be monogamous, because it is largely confined to sexual interactions within marriage, through the selective use of contraception (the genetic level).

In both cases, knowledge of the marriage system provides limited insight into mating behavior and its reproductive implications. This is why it is problematic to use information on the marriage system to draw inferences about other levels in the framework. Unfortunately, this practice is, to some degree, inevitable. An accurate description of variation in all relevant behaviors would require individual-level genetic data coupled with long-term behavioral observations; these could then be summarized into indices suitable for comparison within and across populations. For obvious practical and ethical reasons, such data are not readily available. As a consequence, studies into the evolution of marriage systems largely rely on typological classifications like the one outlined above, based on the number of concurrent spouses allowed. Where individual-level data are available (e.g. estimates of reproductive success), these are usually based on self-reports or historical records (e.g. documenting the number of spouses and children), rather than on genetic assessment.

In sum, capturing in a systematic manner the diversity of possible marital and mating arrangements, within and across societies, is riddled with conceptual and empirical difficulties. It will be useful to keep in mind some of the caveats outlined here as we turn to the discussion of marriage system evolution. 


\section{Evolutionary perspectives on marriage systems}

The 1960s and 1970s saw the development of a conceptual framework for application of evolutionary principles to the study of behavior. This framework was enthusiastically, and in some cases perhaps uncritically, extended to our species. In particular, the framework promised to situate human behavior within a broad cross-specific perspective, while at the same explaining its variation within and across groups. Current evolutionary approaches to human behavior derive from this framework, in a more or less direct line of descent (see discussion in Laland and Brown, 2011).

Several of the general themes that run through the literature on the evolution of marriage systems developed in this context, grounded in the logic of asymmetry in investment between the sexes (Trivers, 1972). This is the idea that in species with sexual reproduction the sex difference in gamete size leads to divergence in behavioral strategies. By definition, males produce smaller gametes than females. The result of this initial difference in investment is a typical pattern where females care for the offspring while males seek out additional mates; females are selective in their choice of partners, whereas males are less discerning. This paradigm is currently being revised within biology, to move away from the standard behavioral roles and mating strategies attributed to the two sexes (see discussion in Kokko and Jennions, 2012). The revisions are trickling from biology into anthropology (e.g. Brown et al., 2009; Schacht et al., 2014), but stereotypical assumptions about the behavior of men and women derived from the "classical" paradigm continue to dominate.

Broadly, studies of the evolution of marriage systems address two sets of questions, relating to variation within and across societies. Where polygamous marriage is allowed, what determines whether an individual marries one or more spouses? And what determines whether the marriage system is monogamous or polygamous in the first place? A third aspect of interest lies at the interface between the two sets of questions, namely the relationship between individuallevel outcomes and the rules and norms encoded in the marriage system. For example, does the marriage system emerge through a "bottom-up" process (e.g. it reflects the prevalent strategy within a group) or through a "top-down" process (e.g. it reflects the strategy of dominant individuals within the group)? While important, this aspect remains largely unexplored in the evolutionary literature. 
Below I outline general themes that run through this literature, with a final word of caution. Although explanations are often phrased in terms of motivations, preferences, choice, strategies, etc., they do not rest on conscious decision-making by individuals occupied with weighing the fitness outcomes of the different options open to them. Rather, individuals act "as if" their behavior were driven by such reckoning, possibly mediated by conscious decision-making operating in concert with, or against, the expectation of inclusive fitness maximization (Chisholm and Burbank, 1991). A related issue is that an individual's choice or strategy need not reflect his/her own motivations or preferences: as noted above, it may be the outcome of some degree of "negotiation" with third parties, such as parents or other kin.

\subsection{Polygyny as the "default" mating and marriage system}

The central idea derived from the classical paradigm of behavioral biology is that in humans, as in other mammals, polygyny is the "default" mating system (e.g. Low, 2003, 2007). Men, like males in other species, seek to increase the number of matings, often through intrasexual competition. Women's strategies, like those of females in other species, revolve around intersexual choice, possibly in response to the pattern of resource distribution.

If the marriage system is viewed simply as the cultural amplification of the mating system, a "baseline" of polygynous mating conveniently explains the prevalence of polygynous marriage systems across societies (82\% in the Standard Cross-Cultural Sample; Figure 1). The underlying narrative is that men will pursue plural mating as their preferred strategy if individual circumstances allow, and a polygynous marriage system best accommodates this tendency for men to seek polygynous mating whenever possible. The actual pattern of marital arrangements within a polygynous marriage system is the result of variation in individual circumstances.

Two sets of observations are typically used to corroborate this narrative. First, in societies that allow polygynous marriage, polygynously married men tend to be better off, reproductively, than their monogamously married peers. Second, across historical and geographical contexts, dominant men (i.e. those in control of social and/or physical resources, such as political status and material wealth) have directed substantial amounts of effort into the acquisition of multiple mates, in some cases (though not exclusively) through polygynous marriage (Betzig, 1982, 1986). Assuming that dominance enables men to "get their way", this is taken to indicate that polygynous mating, possibly through polygynous marriage, is what men ultimately and 
universally aspire to.

However, this view rests on an overly simplified approach to the relationship between marriage, mating, and reproduction. The underlying assumption is that reproductive success (number of offspring) increases linearly with mating success (number of mates), but this is not necessarily the case (Brown et al., 2009). For example, where males contribute heavily to parental investment, reproductive success increases less than linearly with mating success. The limited evidence available for humans, reviewed in Brown et al. (2009), shows that the relationship between mating and reproductive success varies across populations, for both men and women. This suggests that we should not expect men to always benefit from, and hence seek, polygynous mating.

With reference to the nested framework outlined above, a further difficulty arises from conflation of the marriage and mating levels. Even where men do benefit, reproductively, from polygynous mating, this does not imply that they should always seek polygynous marriage as a result. As we shall see below, in some ecological and social settings polygynous marriage may entail costs for men, which can be avoided through alternative arrangements (Fortunato and Archetti, 2010; Fortunato, 2012). In these contexts, the optimal strategy for men may involve non-polygynous marriage, possibly coupled with polygynous mating (e.g. through extra-marital sexual relations).

Finally, recent empirical evidence shows that plural marriage does not necessarily result in long-term reproductive benefits for men. Among the horticultural Pimbwe of Tanzania, number of wives is negatively associated with reproductive success. In this contemporary group polygynous marriage is allowed but uncommon, and plural marriage is typically the result of remarriage following divorce (Borgerhoff Mulder, 2009). In a pre-industrial agricultural Finnish population, number of wives was positively associated with number of children, but it had no effect on number of grandchildren. In this historical group monogamous marriage was enforced, and plural marriage was exclusively the result of remarriage following death of one's spouse (Pettay et al., 2014).

Taken together, these theoretical and empirical insights point to a more nuanced approach to the strategies, motivations, and preferences of men and women than has been generally assumed in the evolutionary literature. As we shall see in the following sections, the view that polygynous marriage best accommodates men's aspiration to mate polygynously has had 
several repercussions for the study of both polygynous and non-polygynous marriage systems. Somewhat paradoxically perhaps, the strategies, motivations, and preferences of women have received most attention in the context of polygynous marriage - why would a woman marry a married man? Further, non-polygynous systems have typically been approached from the perspective of men, who are viewed as "relinquishing" polygyny in these systems, possibly driven by peculiarities of the ecological and social environments. As a consequence, explanations have focused on the reproductive implications of non-polygynous marriage systems for men, to demonstrate that relinquishing polygyny "makes sense", evolutionarily, from their perspective in these environments. Less attention has been paid to the reproductive implications of nonpolygynous marriage systems for women, and to potential conflict and feedback between male and female strategies (Borgerhoff Mulder, 2009; Borgerhoff Mulder and Rauch, 2009).

\subsection{Polygynous marriage as resource defense polygyny}

Emlen and Oring (1977) introduced a classification of animal mating systems based on the ability of individuals to monopolize mates. One aspect of the classification captures the means through which individuals succeed in this endeavor. For example, in "female defense polygyny" (also known as "harem defense polygyny") males control access to mating opportunities directly, by guarding groups of females from potential competitors. By contrast, in "resource defense polygyny" males exert control indirectly, by monopolizing resources essential to female reproduction (e.g. food or breeding sites).

This classification has found extensive application in the study of marriage system evolution (e.g. Flinn and Low, 1986; Marlowe, 2000). Broadly, the resource defense polygyny model applies where men acquire multiple wives by controlling social resources (e.g. age, political authority) or physical ones (e.g. material wealth). The distinction with the female defense polygyny model is somewhat blurred, however, because men's ability to control access to women directly (e.g. in the harems of despotic rulers; Betzig, 1982, 1986) is strongly mediated by their ability to appropriate resources.

Across societies, the degree to which men vary in controlling resources tends to vary with the subsistence system. The resource defense polygyny model applies straightforwardly in nonforaging societies, in which the subsistence system involves the accumulation of physical resources and their transfer across generations, and material wealth may be used directly to 
acquire a bride (i.e. through bridewealth, where the groom's family transfers livestock and/or other property to the bride's family). In foraging societies the model may apply where men vary in the degree of control over food-extraction sites (Sellen and Hruschka, 2004) or over social resources (e.g. where age is the basis for access to wives; see discussion in Irons, 1983, pp. 180-185). However, in the majority of these societies there is limited variation across men in the degree of resource control, and the extent of polygynous marriage is therefore limited (e.g. the prerogative of particularly successful hunters). Alexander et al. (1979) labelled this system "ecologically imposed monogamy" (to distinguish it from "socially imposed monogamy", discussed below; note that monogamous marriage is enforced in the latter, but typically not in the former).

\subsection{The polygyny threshold model, female choice, and male coercion}

Applied to marriage system evolution, the resource defense polygyny model is typically linked to the polygyny threshold model, even though the two do not overlap entirely (see Emlen and Oring, 1977). The polygyny threshold model (Orians, 1969) was developed to explain the occurrence of territorial polygyny in birds, a mating system in which multiple females nest in the territory occupied by their mate (Searcy and Yasukawa, 1989). It applies to situations where males occupy territories of varying quality, and a female's reproductive success increases with the quality of her mate's territory, but it decreases if she has to share resources (e.g. male care, food, nest sites) with other females. Thus, the female incurs a cost by mating with an already-mated male, in the sense that she would be better off mating with the same male, but as his only mate.

The polygyny threshold model specifies under what conditions it pays for the female to mate with an already-mated male despite this cost. For example, a female may be better off as the second mate of an already-mated male on a high-quality territory, than as the only mate of an unmated male on a territory of considerably lower quality. In this example, the polygyny threshold is the minimum difference in territory quality between the two males to make the polygynous arrangement advantageous for the female over the monogamous arrangement. According to this model, the occurrence of territorial polygyny in birds indicates that females are sufficiently compensated for the cost of polygynous mating through access to better quality territories (Searcy and Yasukawa, 1989). 
Extended to polygynous marriage, this line of reasoning suggests that women may be better off marrying a man who is already married, if he controls sufficiently better resources (in terms of quality and/or quantity) than any of the available unmarried men. A common interpretation, introduced by Chisholm and Burbank (1991), focuses on the reproductive outcomes of women in different marital arrangements within a population. Specifically, if the wives of polygynous husbands do at least as well as the wives of monogamous husbands, this is taken to indicate that polygynous marriage is the result of female choice: the potential costs of sharing resources with co-wives are compensated by access to better resources. If they do worse, then polygynous marriage is viewed as the result of male coercion: women are "forced" into polygynous arrangements against their best interest and suffer costs. In this context, male coercion does not involve physical coercion: for example, women may have to tolerate co-wives because they do not have access to other men, or because social norms prevent them from leaving their husbands.

While pervasive in the study of marriage systems (e.g. Lawson and Uggla, 2014, for a recent review), this interpretation rests on a distortion of the framework developed by Searcy and Yasukawa (1989) to explain the occurrence of territorial polygyny in birds. In the original formulation of the framework, under male coercion males are able to physically force females into polygynous arrangements (e.g. through herding or by preventing females from moving off, as occurs in some species of ungulates). By contrast, female choice encompasses a hierarchy of models, some involving reproductive costs for females in polygynous arrangements (e.g. femalebiased sex ratios leading to unavailability of unmated males), and others involving no costs (e.g. females recouping the costs of sharing with the male's other mates, through access to better resources). In other words, the polygyny threshold model is only one of a suite of female choice models in the Searcy and Yasukawa (1989) framework. Therefore, it is incorrect to seek to discriminate between male coercion and female choice models based on evidence for or against compensation of the costs of polygynous arrangements to females (an issue discussed already extensively by Searcy and Yasukawa, 1989 and, later, by Borgerhoff Mulder, 1990 in the context of marriage systems).

In short, in the Searcy and Yasukawa (1989) framework costs of polygyny to females are compatible with both male coercion and female choice; in the re-formulation of the framework by Chisholm and Burbank (1991) costs of polygyny to females point exclusively to male coercion. An unfortunate consequence of the conceptual distortion introduced by Chisholm and Burbank 
(1991) is undue emphasis on male coercion, which is commonly invoked to explain worse outcomes for the wives of polygynous men, compared to the wives of monogamous men. This may partly explain why we have limited understanding of the motivations, or constraints, that lead women into polygynous arrangements, in the face of substantial empirical work focusing on women's outcomes in polygynous marriage systems.

On a related note, the motivations and preferences of men are also poorly understood. This is not surprising, given the emphasis in the evolutionary literature on polygyny as the default mating and marriage system, possibly compounded by a bias in empirical work towards subSaharan African societies (Winking et al., 2013). In these societies, polygynous marriage is often associated with prestige, wealth, and status for men; further, multiple wives and their children can be an economic asset, contributing labor to productive activities (Holy, 1996, pp. 63-66). Albeit limited, recent empirical evidence for the forager-horticulturalist Tsimane of Bolivia suggests that similar attitudes are not universal (Winking et al., 2013). In this contemporary population polygynous marriage is allowed but exceedingly rare (and typically sororal, i.e. cowives are sisters), and both men and women find it less preferable than monogamous marriage. Monogamously married men have no aspiration towards polygyny, and they seem unable to identify any benefits associated with it, citing a lack of resources as the chief difficulty that arises in polygynous arrangements, followed only distantly by conflict between co-wives.

\subsection{Monogamous marriage as socially imposed monogamy}

As we saw above, monogamous marriage is enforced in a small but non-trivial fraction of societies (17\% in the Standard Cross-Cultural Sample; Figure 1). Within an evolutionary framework, explaining the origin of this system against a background of default polygyny presents a challenge. Why would dominant men devise, or allow, a marriage system that removes their prerogative to multiple wives? It seems reasonable to assume that, throughout history, these men have influenced, and to some degree directed, the development of rules and norms encoded in kinship and marriage systems to suit their own interests.

One proposal is that the emergence, maintenance, and later diffusion of such a system across societies was driven by intergroup competition: dominant men have most to gain from success in competition with other groups. In particular, Alexander et al. (1979) proposed that the enforcement of monogamous marriage in stratified societies served to reduce within-group 
competition among men for access to potential wives, thereby increasing the competitive ability of these societies in between-group conflict. In other words, monogamous marriage emerged as a mechanism of reproductive leveling, that served to suppress differences in reproductive success among men. Such a mechanism was a prerequisite for the rise, and persistence, of large nation states. Alexander et al. (1979) termed this system "socially imposed monogamy" (as distinct from "ecologically imposed monogamy", discussed above).

While intuitive, this proposal is not easily reconciled with broad empirical patterns (Fortunato and Archetti, 2010). First, the emergence of monogamous marriage long predates the establishment of large nation states (Herlihy, 1995; Scheidel, 2009). Additionally, the patterned present-day distribution of this marriage system across human societies, suggestive of an association with large nation states, may be the result of an early origin in the history of Indo-European-speaking societies, coupled with diffusion to descendant groups and, later, with processes such as imposition on other groups through conquest (Fortunato et al., 2006; Fortunato, 2008, 2011).

Second, the proposal rests on the key assumption that a monogamous marriage system leads to a substantial reduction in the variance in male reproductive success compared to a polygynous marriage system; in the classical paradigm of behavioral biology, variance in reproductive success underlies competition for access to mates. However, the limited comparative data on male reproductive success available for a sample of societies with monogamous and polygynous marriage systems fail to support this assumption (Fortunato and Archetti, 2010). Consistently, detailed analysis of individual-level data for a pre-industrial agricultural Finnish population shows that variance in male reproductive success, and the associated strength of intrasexual competition, can be substantial even in a monogamous marriage system, driven by moderate rates of remarriage following widowerhood (Courtiol et al., 2012).

Finally, recent theoretical revisions of the classical paradigm of behavioral biology (reviewed in Kokko and Jennions, 2012) challenge another key assumption underlying the proposal, namely that the relative "shortage" of potential wives caused by polygynous marriage inevitably results in increased within-group competition among men. These revisions suggest that male mate competition may be less intense if there is a relative shortage of females available for mating, not more (see discussion in Schacht et al., 2014). In line with the theoretical developments, comparative data on the opportunity for sexual selection (a standardized measure of variance 
in reproductive success) across a sample of small-scale, non-industrial societies suggest that the degree of mating competition among men is lower where the sex ratio of the mating pool is more male-biased (Schacht et al., 2014).

In sum, if intergroup conflict did indeed play a role in the emergence, maintenance, and later diffusion of monogamous marriage systems, a more nuanced proposal is required that can account for broad empirical patterns, alongside recent theoretical developments.

\subsection{Monogamous marriage as "monogamous inheritance"}

An alternative proposal explains the emergence of monogamous marriage as a form of "monogamous inheritance" - effectively a mechanism to channel a man's physical resources to the children of a single wife. In particular, Fortunato and Archetti (2010) investigated whether monogamous marriage can be understood as the outcome of strategic male and female behaviors linked to the allocation of resources to the next generation. Counterintuitively, where this arrangement produces the highest reproductive returns on the investment of resources into future generations, dominant men have most to gain from a monogamous marriage system, because they control the most resources. Further, to the extent that polygynous mating is tolerated alongside monogamous marriage, this proposal does not hinge on reduction in the variance in male reproductive success through monogamous marriage. In this respect, it can better accommodate the distinction between the marriage and mating levels than, for example, the proposal that monogamous marriage is a mechanism of reproductive leveling. At the same time, the theoretical model underlying this proposal (described in Fortunato and Archetti, 2010; Fortunato, 2012) does not consider variation among men in the degree to which they control resources, thus this factor remains unexplored.

Fortunato and Archetti (2010) identified two conditions that may make monogamous marriage advantageous over alternative arrangements. First, monogamous marriage coupled with unigeniture (i.e. one individual inherits all or most of the resources) can be used to avoid partitioning resources among multiple heirs. For example, in monogamy with primogeniture the wife's first-born child (usually the first-born son) is the designated heir, to the full or partial exclusion of all other children. In polygynous marriage unigeniture typically applies within sets of children by the same mother. For example, in polygyny with primogeniture the first-born son of each wife may be the designated heir among his full siblings. Linking back to the discussion 
above of the motivations and preferences of women, the polygynous arrangement reflects how each wife (or her kin on her behalf) may require a share of the husband's resources as a condition of marriage. In other words, women may refuse marriage to a married man if inheritance were exclusively by the offspring of the first wife (Fortunato, 2012). As we shall see below, this structural difference in inheritance between monogamous and polygynous arrangements suggests a link to the type of resources transferred, and therefore to the subsistence system.

The second condition that may make monogamous marriage advantageous over alternative arrangements is that women may grant higher fidelity to husbands who marry monogamously over those who marry polygynously. If this is the case, a man's potential reproductive gain from polygynous marriage (i.e. the production of children by multiple wives) may be offset by a loss in terms of reduced paternity, to the point that he may be better off marrying monogamously. In this case, both spouses stand to gain from monogamous marriage: the husband benefits from investing resources "safely" in those individuals in the next generation who provide the potentially highest reproductive returns (i.e. his wife's children), and the wife benefits from exclusive investment of her husband's resources in her own children.

This proposal is compatible with broad patterns in the history and distribution of marriage systems - namely, why monogamy has prevailed across societies of Europe and Asia practicing intensive agriculture (i.e. plough or irrigation agriculture) and first emerged in these regions, whereas polygyny has prevailed across sub-Saharan African societies with subsistence systems based on extensive agriculture (i.e. horticulture, or hoe agriculture) or pastoralism (Goody, 1976). In intensive agriculture high productivity results in scarcity of land, and division of estates among multiple heirs over the generations leads to plots of land that are too small to sustain a household, effectively depleting the value of the estates. In horticulture scarcity of land is unlikely because productivity is low, and in pastoralism the reproduction of livestock acts as a buffer against scarcity. As a result, productivity is constrained by ownership of land in intensive agriculture, and by availability of labor in horticulture and pastoralism. This difference in the type of resources transferred, itself linked to the subsistence system, may have driven the emergence of monogamous marriage as a mechanism of "monogamous inheritance" in the agrarian societies of Europe and Asia.

Several predictions can be derived from the proposal, for testing against data in the archaeological, historical, and ethnographic records (Fortunato and Archetti, 2010). For example, we 
expect to find evidence for an early origin of monogamous marriage, linked to the development of intensive modes of production, and possibly coupled with norms promoting fidelity (e.g. ideologies of honor, emphasis on female virginity at marriage). This prediction is compatible with the broad historical patterns discussed above with reference to socially imposed monogamy. Further, we expect to see evidence of transitions from a polygynous to a monogamous marriage system (e.g. decreasing rates of polygynous marriage) linked to declines in availability of land, as one of a host of mechanisms that serve to limit the number of heirs in a given household. Finally, in the ethnographic record we expect to find an association between monogamous marriage and inheritance of resources by a man's wife's offspring (Fortunato, 2009). Note that, for the most part, these predictions relate to the first condition identified by Fortunato and Archetti (2010). Predictions relating to the second condition may be harder to validate, given the difficulty of obtaining reliable comparative data on paternity rates, for both (pre-)historical and contemporary populations.

\subsection{Polyandrous marriage as a response to ecological challenges}

As we saw above, only $1 \%$ of societies in the Standard Cross-Cultural Sample are coded as polyandrous (Figure 1). This is likely an underestimate, however, reflecting a bias in anthropology towards a narrowly focused set of classic ethnographic descriptions (Starkweather and Hames, 2012). With one exception (the historical population of the Marquesas Islands in the South Pacific; see discussion in Harrell, 1997, pp. 267-271), these pertain to societies in the Himalayan regions of India, Nepal, and Tibet (discussed below). Starkweather and Hames (2012) recently identified several additional cases in the ethnographic record, noting that they have received limited attention in the study of marriage system evolution.

Two key differences between "classical" and "non-classical" polyandrous marriage systems are that the incidence of polyandrous unions tends to be considerably higher in the former, and that polygyny alongside polyandry is found in the former but not in the latter (Starkweather and Hames, 2012). Recall that terms that more accurately describe the co-occurrence of the two forms of plural marriage ("polyandrogyny" and "polygynandry") are used rarely and inconsistently in anthropology. Below I use the term "polyandrogyny" for systems where both sexes vary in number of spouses, but women are more variable than men (Shuster and Wade, 2003, p. 161). 
Our understanding of marriage systems where plural concurrent husbands are allowed is rather limited, perhaps as a result of these and other biases (e.g. the near-exclusive focus on outcomes for men). Broadly, this phenomenon is viewed as a response to peculiar social and/or ecological conditions, such as an unbalanced sex ratio leading to severe scarcity of marriageable men or a circumscribed, harsh ecology requiring the pooling of male labor (see reviews in Levine and Silk, 1997; Starkweather and Hames, 2012).

For example, a particular combination of ecological conditions may explain why some societies in the Himalayan regions of India, Nepal, and Tibet resort to fraternal polyandrogynous marriage, where one set of brothers is married to a single wife (see review and discussion in Barrett et al., 2002, pp. 224-233). As in other intensive agricultural societies of Europe and Asia, the risk of land scarcity is high (in this case through low carrying capacity rather than through increased productivity and subsequent population growth). At the same time, the land requires high labor input and yields low productivity, as in the extensive agricultural societies of sub-Saharan Africa (Fortunato, 2009, p. 38). In this ecological context, fraternal polyandrogynous marriage may serve two functions (Goody, 1976, 1990). The first is to limit the number of heirs to an estate: the "monomarital principle" (Goldstein, 1971) limits the number of wives whose children have claims to the estate. The second function is to concentrate the labor of a set of brothers into the same household, ensuring an adequate workforce against the low productivity of the land.

From an evolutionary perspective, if this arrangement is indeed a response to harsh ecological conditions, a man in a polyandrous or polyandrogynous union is expected to do better, reproductively, than his peers in monogamous or polygynous unions (taking into account his own reproductive outcomes and those of his brothers). However, tests of this prediction are inconclusive, marred by practical difficulties, for example the relatively small numbers of brothers at a given "rank" within a household and uncertainty in the assignment of paternity among them (see review in Barrett et al., 2002, pp. 224-233). Conceptually, a further difficulty arises from interpretation of the data in an evolutionary context. If a key function of polyandrous/polyandrogynous arrangements is to limit the number of heirs, in the interest of long-term lineage survival (i.e. by keeping the family farm intact), the focus on the reproductive outcomes of individual men is misplaced. Analysis should focus on the reproductive implications for men (and women) as parents, rather than on those for men as husbands (Barrett et al., 
2002, p. 229). Further insight may derive from research into the factors associated with the dissolution of polyandrous/polyandrogynous households when outside options for men become available, such as employment opportunities not linked to the family farm (e.g. Levine and Silk, 1997; Haddix, 2001).

An additional open question relates to broader patterns of variation across societies in the Himalayan region faced with what appear to be similar ecological challenges: not all groups resort to plural concurrent marriage for women or to the same set of inheritance norms. This has led to the suggestion that historical contingency may have played a greater role than ecological factors in shaping the observed distribution of marriage systems in the region (Berreman, 1978).

In sum, of all the marriage systems those involving plural concurrent husbands are the least well understood.

\section{Concluding remarks}

This article has introduced key concepts and general themes in the study of marriage system evolution. The overview has revealed some broad trends. Marriage systems were initially viewed as the cultural "analog" of mating systems; as a result, early work focused on their ecological correlates (e.g. amount of rainfall, parasite load), failing however to uncover clear patterns (see reviews in Low, 2003, 2007). The realization that marriage may have more to do with the transfer of resources across generations than with mating and the production of children is shifting the focus towards the interplay of the marriage system with ecological and social factors.

At the outset, this body of work was firmly grounded in the classical paradigm of behavioral biology, with its emphasis on asymmetries in investment between the sexes. Recent revisions of the paradigm are slowly being incorporated into evolutionary approaches to marriage systems, but classical views continue to dominate (e.g. a bias towards the reproductive outcomes for men; Borgerhoff Mulder, 2009). These revisions suggest a more nuanced approach to conflict and feedback between male and female strategies and their co-evolution with environmental factors. 


\section{References}

Alexander, R. D., Hoogland, J. L., Howard, R. D., Noonan, K. M., and Sherman, P. W. (1979). Sexual dimorphisms and breeding systems in pinnipeds, ungulates, primates, and humans. In Chagnon, N. A. and Irons, W., editors, Evolutionary biology and human social behavior: an anthropological perspective, chapter 15, pages 402-435. Duxbury Press, North Scituate, MA.

Barrett, L., Dunbar, R., and Lycett, J. (2002). Human evolutionary psychology. Palgrave, Basingstoke.

Berreman, G. D. (1978). Ecology, demography and domestic strategies in the western Himalayas. Journal of Anthropological Research, 34(3):326-368.

Betzig, L. L. (1982). Despotism and differential reproduction: a cross-cultural correlation of conflict asymmetry, hierarchy, and degree of polygyny. Ethology and Sociobiology, 3(4):209221.

Betzig, L. L. (1986). Despotism and differential reproduction: a Darwinian view of history. Aldine, New York, NY.

Borgerhoff Mulder, M. (1990). Kipsigis women's preferences for wealthy men: evidence for female choice in mammals? Behavioral Ecology and Sociobiology, 27(4):255-264.

Borgerhoff Mulder, M. (2009). Serial monogamy as polygyny or polyandry? Marriage in the Tanzanian Pimbwe. Human Nature, 20(2):130-150.

Borgerhoff Mulder, M. and Rauch, K. L. (2009). Sexual conflict in humans: variations and solutions. Evolutionary Anthropology, 18(5):201-214.

Brown, G. R., Laland, K. N., and Borgerhoff Mulder, M. (2009). Bateman's principles and human sex roles. Trends in Ecology $\&$ Evolution, 24(6):297-304.

Chisholm, J. S. and Burbank, V. K. (1991). Monogamy and polygyny in Southeast Arnhem Land: male coercion and female choice. Ethology and Sociobiology, 12(4):291-313.

Courtiol, A., Pettay, J. E., Jokela, M., Rotkirch, A., and Lummaa, V. (2012). Natural and sexual selection in a monogamous historical human population. Proceedings of the National Academy of Sciences of the United States of America, 109(21):8044-8049. 
Emlen, S. T. and Oring, L. W. (1977). Ecology, sexual selection, and the evolution of mating systems. Science, 197(4300):215-223.

Flinn, M. V. and Low, B. S. (1986). Resource distribution, social competition, and mating patterns in human societies. In Rubenstein, D. I. and Wrangham, R. W., editors, Ecological aspects of social evolution: birds and mammals, chapter 11, pages 217-243. Princeton University Press, Princeton, NJ.

Fortunato, L. (2008). A phylogenetic approach to the history of cultural practices. In Allen, N. J., Callan, H., Dunbar, R., and James, W., editors, Early human kinship: from sex to social reproduction, chapter 11, pages 189-199. Blackwell Publishing Ltd, Oxford.

Fortunato, L. (2009). The evolution of kinship and marriage systems. Doctor of philosophy in anthropology, University College London. Available from http://discovery.ucl.ac.uk/ $18995 /$.

Fortunato, L. (2011). Reconstructing the history of marriage strategies in Indo-Europeanspeaking societies: monogamy and polygyny. Human Biology, 83(1):87-105.

Fortunato, L. (2012). The evolution of matrilineal kinship organization. Proceedings of the Royal Society B: Biological Sciences, 279(1749):4939-4945.

Fortunato, L. and Archetti, M. (2010). Evolution of monogamous marriage by maximization of inclusive fitness. Journal of Evolutionary Biology, 23(1):149-156.

Fortunato, L., Holden, C., and Mace, R. (2006). From bridewealth to dowry? A Bayesian estimation of ancestral states of marriage transfers in Indo-European groups. Human Nature, 17(4):355-376.

Goldstein, M. C. (1971). Stratification, polyandry, and family structure in central Tibet. Southwestern Journal of Anthropology, 27(1):64-74.

Goody, J. (1976). Production and reproduction: a comparative study of the domestic domain. Cambridge University Press, Cambridge.

Goody, J. (1990). The oriental, the ancient and the primitive: systems of marriage and the family in the pre-industrial societies of Eurasia. Cambridge University Press, Cambridge. 
Haddix, K. A. (2001). Leaving your wife and your brothers: when polyandrous marriages fall apart. Evolution and Human Behavior, 22(1):47-60.

Harrell, S. (1997). Human families. Westview Press, Boulder, CO.

Herlihy, D. (1995). Biology and history: the triumph of monogamy. Journal of Interdisciplinary History, 25(4):571-583.

Holy, L. (1996). Anthropological perspectives on kinship. Pluto Press, London.

Irons, W. (1983). Human female reproductive strategies. In Wasser, S. K., editor, Social behavior of female vertebrates, chapter 7, pages 169-213. Academic Press, New York, NY.

Kokko, H. and Jennions, M. D. (2012). Sex differences in parental care. In Royle, N. J., Smiseth, P. T., and Kölliker, M., editors, The evolution of parental care, chapter 6, pages 101-116. Oxford University Press, Oxford.

Laland, K. N. and Brown, G. R. (2011). Sense and nonsense: evolutionary perspectives on human behaviour. Oxford University Press, Oxford, 2nd edition.

Lawson, D. W. and Uggla, C. (2014). Family structure and health in the developing world: what can evolutionary anthropology contribute to population health science? In Gibson, M. A. and Lawson, D. W., editors, Applied evolutionary anthropology: Darwinian approaches to contemporary world issues, chapter 5, pages 85-118. Springer, New York, NY.

Levine, N. E. (2008). Alternative kinship, marriage, and reproduction. Annual Review of Anthropology, 37(1):375-389.

Levine, N. E. and Silk, J. B. (1997). Why polyandry fails: sources of instability in polyandrous marriages. Current Anthropology, 38(3):375-398.

Low, B. S. (2003). Ecological and social complexities in human monogamy. In Reichard and Boesch (2003), chapter 11.

Low, B. S. (2007). Ecological and socio-cultural impacts on mating and marriage systems. In Dunbar, R. I. M. and Barrett, L., editors, Oxford handbook of evolutionary psychology, chapter 30, pages 449-462. Oxford University Press, Oxford. 
Marlowe, F. (2000). Paternal investment and the human mating system. Behavioural Processes, 51(1-3):45-61.

Mealey, L. (2000). Sex differences: development and evolutionary strategies. Academic Press, San Diego, CA.

Murdock, G. P. and White, D. R. (1969). Standard cross-cultural sample. Ethnology, 8(4):329369.

Murdock, G. P. and Wilson, S. F. (1972). Settlement patterns and community organization: cross-cultural codes 3. Ethnology, 11(3):254-295.

Orians, G. H. (1969). On the evolution of mating systems in birds and mammals. The American Naturalist, 103(934):589-603.

Parkin, R. (1997). Kinship: an introduction to basic concepts. Blackwell Publishers Ltd, Oxford.

Pettay, J. E., Rotkirch, A., Courtiol, A., Jokela, M., and Lummaa, V. (2014). Effects of remarriage after widowhood on long-term fitness in a monogamous historical human population. Behavioral Ecology and Sociobiology, 68(1):135-143.

Reichard, U. H. (2003). Monogamy: past and present. In Reichard and Boesch (2003), chapter 1, pages $3-26$.

Reichard, U. H. and Boesch, C. (2003). Monogamy: mating strategies and partnerships in birds, humans and other mammals. Cambridge University Press.

Schacht, R., Rauch, K. L., and Borgerhoff Mulder, M. (2014). Too many men: the violence problem? Trends in Ecology \& Evolution, 29(4):214-222.

Scheidel, W. (2009). A peculiar institution? Greco-Roman monogamy in global context. The History of the Family, 14(3):280-291.

Searcy, W. A. and Yasukawa, K. (1989). Alternative models of territorial polygyny in birds. The American Naturalist, 134(3):323-343.

Sellen, D. W. and Hruschka, D. J. (2004). Extracted-food resource-defense polygyny in native Western North American societies at contact. Current Anthropology, 45(5):707-714. 
Shuster, S. M. and Wade, M. J. (2003). Mating systems and strategies. Princeton University Press.

Starkweather, K. E. and Hames, R. (2012). A survey of non-classical polyandry. Human Nature, $23(2): 149-172$.

Stevens, J. R. and Gilby, I. C. (2004). A conceptual framework for nonkin food sharing: timing and currency of benefits. Animal Behaviour, 67(4):603-614.

Trivers, R. L. (1972). Parental investment and sexual selection. In Campbell, B., editor, Sexual selection and the descent of man 1871-1971, chapter 7, pages 136-179. Heinemann, London.

White, D. R., Burton, M. L., Divale, W. T., Gray, J. P., Korotayev, A., and Khaltourina, D. (n.d.). Standard cross-cultural codes. Retrieved August 31, 2007, from http://eclectic. ss.uci.edu/ drwhite/courses/SCCCodes.htm.

Winking, J., Stieglitz, J., Kurten, J., Kaplan, H., and Gurven, M. (2013). Polygyny among the Tsimane of Bolivia: an improved method for testing the polygyny-fertility hypothesis. Proceedings of the Royal Society B: Biological Sciences, 280(1756). 